\title{
A van der Waals force-based adhesion study of stem cells exposed to cold atmospheric plasma jets
}

Kobra Hajizadeh

Islamic Azad University

Hassan Mehdian

Kharazmi University

Kamal Hajisharifi ( $\nabla$ hajisharifi@khu.ac.ir )

Kharazmi University

Eric Robert

GREMI, UMR 7344, CNRS/Universit d'Orlans

\section{Research Article}

Keywords: Cold atmospheric plasma, Stem cell, van der Waals force, Cell adhesion, Polarization

Posted Date: March 7th, 2022

DOI: https://doi.org/10.21203/rs.3.rs-1370631/v1

License: (9) This work is licensed under a Creative Commons Attribution 4.0 International License.

Read Full License 


\title{
A van der Waals force-based adhesion study of stem cells exposed to cold atmospheric plasma jets
}

\author{
Kobra Hajizadeh ${ }^{1,2,5}$, Hassan Mehdian ${ }^{3}$, \\ Kamal Hajisharifi ${ }^{3}{ }^{*}$, Eric Robert ${ }^{4}$, \\ 1 Physics department, Faculty of Science, South Tehran Branch, \\ Islamic Azad University, Tehran, Iran \\ ${ }^{2}$ School of Physics, Institute for Research in Fundamental Science (IPM) \\ P.O. Box 19395-5531, Tehran, Iran \\ 3 Department of Physics and Institute for Plasma Research, \\ Kharazmi University, Tehran 15614, Iran \\ ${ }^{4}$ GREMI, UMR 7344, CNRS/Universit d'Orlans, Orlans, France \\ ${ }^{5}$ Research center for modeling and optimization in science and engineering, \\ South Tehran Branch, Islamic Azad University, Tehran, Iran \\ *Corresponding author: E-mail: hajisharifi@khu.ac.ir
}

February 28, 2022

\begin{abstract}
Cold atmospheric plasma has established its effect on cell adhesion. Given the importance of cell adhesion in stem cells, the current study looked at the effect of plasma treatment on Human Bone Marrow Mesenchymal Stem Cells (HBMMSCs) adhesion by which the differentiation and fate of cells are determined. In this paper, adhesion modification was investigated not just among cell- ECM, but also between suspended cells, and enhanced adhesions were found in both circumstances. Regarding the previous works, increasing the cell-ECM adhesion during the plasma therapy could be mostly attributed to enhancing the production and activity of integrin proteins, while at the suspension condition, we have showed that this increasing is due to the enhancing in van der Waals forces (VDWFs) between the cells. Considering the importance of van der Waals forces at the cellular level, the effect of cold plasma on VDWFs and so its effect on adhesion were investigated in this work for the first time, to the best of our knowledge. For this purpose, employing the semi-empirical methods, the role of the plasma therapy on the VDWF between the cells has been studied at three levels; a) plasma-induced dipole formation, b) Hammaker coefficient modification of culture medium, and c) cell roughness modification. We believe that, the present work gives a new physical insight in studying the plasma therapy method at the cellular level.
\end{abstract}

Keywords: Cold atmospheric plasma, Stem cell, van der Waals force, Cell adhesion, Polarization. 


\section{Introduction}

Cold Atmospheric Plasma (CAP) with its great potential in various fields including medicine [1], biology, and physiology [2,3] has recently demonstrated its therapeutic effects, particularly in cancer therapy [4] and wound healing [5-7]. Although the presence of reactive oxygen/nitrogen species (RONS) in the physical environment of the plasma plume and plasma-activated medium has been introduced as the primary factor in atmospheric plasma-based therapies, the effect of another crucial factor such as electric field inducing cell polarization leading to dipole formation is probably of key importance. In this regard, plasma can affect the van der Waals, VDW, forces between cell-cell and cell-ECM (Extra cellular Matrix) in two ways; a) dipole generation, as a consequence of plasma-induced electric field and, b) cell-surface roughness modification, caused by plasma treatment [8]. Moreover, the effect of RONS on cell-cell and cell-ECM adhesion illustrated schematically in Fig.1 has been long-established by many authors since quite a long time [9-13]. Given the large amount of RONS produced during plasma therapy together with the formation of dipoles, it is very likely that media exposure to plasma affects cell adhesion and maybe that is the reason of rounded shape detachment pattern during the plasma therapy [14].

The regulation of cell adhesion is of special importance for stem cells. Not only is cell differentiation influenced by its shape at the end of the adhesion process, but also adhesion determines the timing of cell migration onset/cessation as well as the migration pathway [15]. On the other hand, it is very essential in cell communication and regulation [16]. The cell-ECM mechanical communications can manage and control cell performance and function $[17,18]$. The role of cell adhesion is much more crucial than merely binding two cell surfaces together or attaching cells to the ECM. Cell adhesion indeed triggers signaling pathways to activate and modulate cell function leading to physical changes in cell properties such as stiffness, motility, and cell-ECM interactions. There are various mechanisms of adhesion, including electrostatic interactions [15,19-22]. In this regard, Kendall and Robert [23] showed that among the electrostatic forces, van der Waals is the key force involved in adhesion than any others. Despite the weakness of this force compared to hydrogen and ionic bonds, two important factors make it very effective in adhesion; a) its ubiquity across all molecules and, b) Cell size, for which the role of VDWF will be very significant $[24,25]$. Therefore, beside the established effect of RONS on cell-cell and cell-ECM adhesion [9-13], any factor that affects the VDW force causes a change in cell adhesion, with the effect that, changes the behavior, function, and fate of cells [26,27]. The change of cell adhesion leads to a wide range of diseases, including osteoarthritis [28], cancer $[24,29,30]$, osteoporosis [25,31], and atherosclerosis (atherosclerosis) [32-34]. So, the investigation and control of cell adhesion should be accounted for, in plasma based therapies, given that any change of cell adhesion features might be considered as a warning indicator for cell health.

Stem cell adhesion is of two essential importance, firstly the selectivity of cell adhesion and secondly, its importance in biomaterials, which plays a crucial role in tissue and organ formation. Therefore, to develop any new therapeutic method (e.g. Plasma-based therapies), it is important to study its effects on adhesion of the cells. According to previous researches [34-36], at a first glance, plasma can activate integrin, as one of the key molecules in cell adhesion. Haertel, in 2014 found that CAP affects integrin expression, so it can alter cell-ECM adhesion $[32,33]$ but, regarding the effect of plasma on cell polarization and resulting in dipoles formation (Fig. 1) plasma can also contribute 


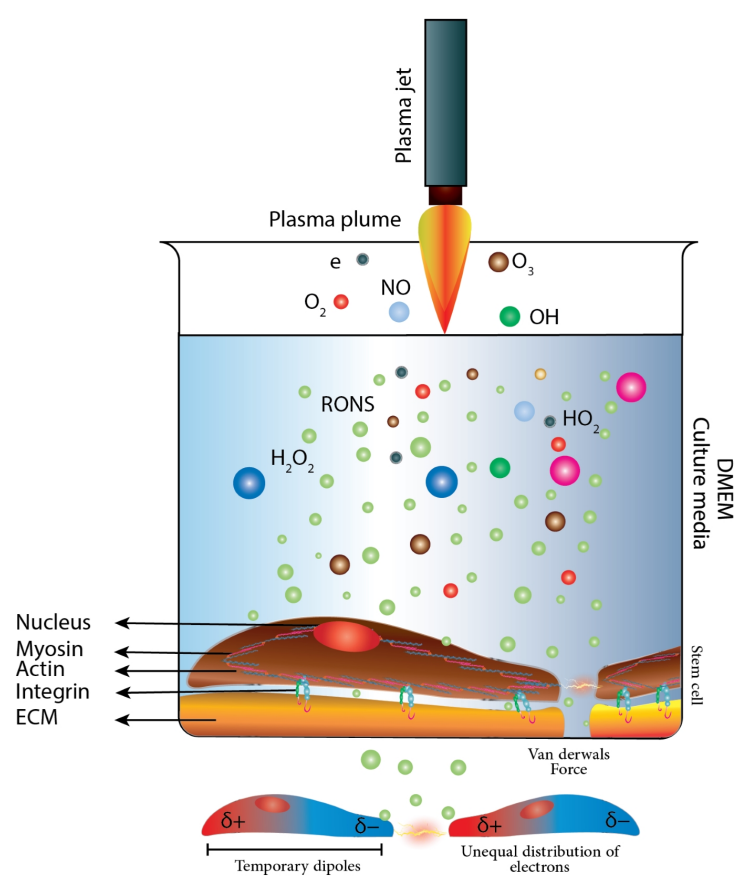

Figure 1: A schematic of Plasma interactions on aqueous media. Electric field, ions, electrons, neutrals, and reactive oxygen and nitrogen species is produced. The charge distribution of Cell is changed and creates electric dipoles

to cell adhesion modification through changing the VDWF between cell-cell and cell-ECM. Furthermore, it modifies the surface roughness which, in turn, affects VDWF [8]. To the best of our knowledge, the effect of plasma on VDWF between cells has not been studied yet, and so its effect on stem cell adhesion has not been fully elucidated. In this regard, in present paper, we try to address these two phenomena. De-adhesion, and shear stress assay, along with morphological studies, have been used to evaluate adhesion strength and cell elasticity. The conductivity of cell culture media is evaluated to study the VDWF modification.

\section{Materials and METHODS}

\subsection{Cell Culture}

Human Bone Marrow Mesenchymal Stem Cells (HBMMSCs, provided from: Stem Cell Technology Research Center (STRC) Tehran, Iran) cultured at $37^{\circ} \mathrm{C}$ in a humidified atmosphere containing 5\% $\mathrm{CO}_{2}$ in DMEMF12 (Sigma Aldrich) supplemented with 10 fetal bovine serum (FBS, Sigma Aldrich), and 1\% penicillin/streptomycin (Sigma). Cells were maintained in cell culture flasks $25 \mathrm{~cm} 2$ (Bio-One) and the media was changed every three days. Having confirmed the cell confluence of $90 \%$ for cells in the flask, they were collected by trypsin - EDTA (Sigma Aldrich) and reseeded. Cells were transferred to $3.5 \mathrm{~cm}$ (in diameter)-Petri dishes after passage number 3 , and some cells were cultured on coverslips for various objectives. Before trypsinization, cells were cultured at $37^{\circ} \mathrm{C}$ for 
24 hours to prepare them for the de-adhesion assay. Petri dishes were exposed directly to the plasma output of the CAP system, ignited at both high $(35 \mathrm{~W}$, representing a high risk area [37]) and low (20W, representing a safe area [37]) power ranges of the generator. Finally, varied doses of plasma-activated water, PAW, were applied to some of the coverslips. As previously stated [37], the PAW has been classified as; 1) high dose: the power of plasma generator $35 \mathrm{~W}$ and the exposure time of $90 \mathrm{~s}$ and, 2) low dose: the power of plasma generator $20 \mathrm{~W}$ with exposure time less than $90 \mathrm{~s}$. After treatment, cells were incubated under the same conditions for another twenty-four hours.

\subsection{Cold Atmospheric Plasma (CAP) device}

The Argon-fed DBD-plasma Jet of Kharazmi University-Plasma lab used to treat Stem Cells is an RF (13.56MHz) Plasma Jet, see our previous paper [37]. Its power set to $20 \mathrm{~W}$ and $35 \mathrm{~W}$ (as no-risk and high-risk limits of generators power for treating the stem cells [37]) and gas flow rate of 1 slm. The bulk plasma temperature has been measured to $37^{\circ} \mathrm{C}$. The spectrum of our plasma can be found in reference [37] which shows the generation of the some important reactive species generated with this device $(\mathrm{OH}, \mathrm{O}$, $\mathrm{NO})$.

\subsection{DAPI staining and Fluorescence imaging}

Cells were stained with DAPI (4',6-diamidino-2-phenylindole) according to "Cold Harbor Spring" protocol (see ref. [37] for details) to follow the cell dynamics and shapes. Briefly, cultured cells were washed, twice, with phosphate-buffered saline (PBS), fixed in $4 \%$ paraformaldehyde for 10min, and permeabilized with $0.5 \%$ Triton X-100 for $15 \mathrm{~min}$ at room temperature. Then, cells were incubated in PBS for $1 \mathrm{~h}$ at room temperature. After incubation, cell nuclei were labeled with DAPI (1: 500, Sigma-Aldrich). The samples were mounted on the stage of the microscope, using slides. Imaging was performed using a Nikon microscope equipped with an incubator to control temperature, humidity, and $\mathrm{CO}_{2}$. Images were recorded with a $\mathrm{CCD}$ camera.

\subsection{De-adhesion assay}

The resistance of cells in detachment from the substrate, called de-adhesion, is used as a suitable parameter to measure cell adhesion. Mechanical forces that are able to separate cells from the substrate are used as a tool to determine the extent of cell adhesion [38,39]. In this study, to quantify cell adhesion dynamics, use has been made of "de-adhesion assay" [40], in which the cells were separated from the external matrix with trypsin and cellular contraction was observed before whole-cell detachment. To quantify the kinetics of cell contraction, the average normalized area of cell contact with the substrate is evaluated temporally. In this regard, the surface area of the cells was calculated in a time-dependent manner. The difference between the cell area in time $t, A_{t}$, and the initial one, $A_{\text {initial }}$, (i.e., $\left.A_{\text {initial }}-A_{t}\right)$ normalized to the difference between the initial and final cell surface, $A_{\text {final }}$, (i.e., $A_{\text {initial }}-A_{\text {final }}$ ) were measured at each time. Finally, the time constants were calculated by fitting the normalized cell surface area vs. time into a sigmoid curve. 


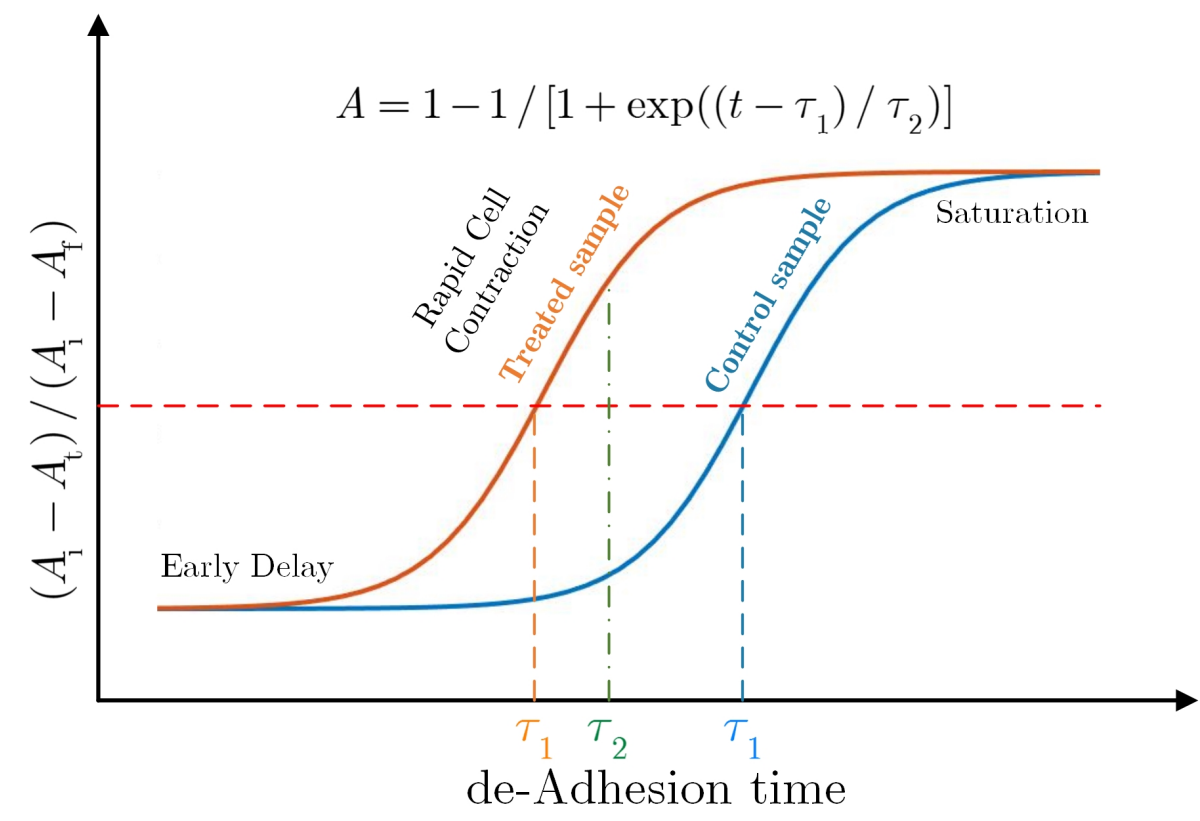

Figure 2: The normalized cell surface area VS de-adhesion time for treated and untreated (control) cells.

An example can be found in Figure 2, where treated (red curve) and untreated (blue curve) cells make sigmoid curves and each of them consists of three distinct stages: early delay, rapid cell contraction, and saturation. Two time-constants apparent in this diagram $\tau_{1}$ and $\tau_{2}$, indicate cell adhesion and cell elasticity, respectively. The first time constant, $\tau_{1}$, is the time to decrease the cell surface area to half, and the second time constant, $\tau_{2}$, demonstrates the reduction of another $25 \%$ of the cell surface area to reach seventy-five percent of the total area.

\subsection{Focal Adhesion}

The importance of focal adhesion (FA) stems from the fact that it is involved in actin cytoskeleton organization. FAs reveal physical cell-ECM contact as well as internal/external signaling [15]. Therefore, quantitative analysis of FAs is crucial for understanding important biological processes including cell shape, motility, cell proliferation, and differentiation $[16,17]$. Given that cells can form different FAs at the micrometer scale, their quantitative analysis requires optimized image analysis approaches. Analysis steps were performed by combining LOG3D and CLAHE plugins from the NIH (National Institutes of Health) program [41].

\subsection{Shear Stress Assay}

Applying shear-stress assay, the importance of shear stress in plasma-induced cell detachment was evaluated. Use has been made of a syringe pump to form a fluid flow of the cell culture medium. Having applied a 3 minute-flow of the medium on the stem cell, the remaining cells were counted. For this purpose, a channel (17 microns in diameter) was needed inside the PDMS, to connect to the syringe pump (Fig. 4) and apply the flow to 
the cells.

\subsubsection{Creating the microfluidic channel}

The microfluidic channel was created using soft lithography:

(A) A spin-coating with a negative light-resistance was applied to the silicon wafer, which was then soft baked for a few minutes. It was placed under a mask and put on a hot plate for a few minutes after exposure, preceded by a short resting time, using a wafer aligner. Following that, the wafer was expanded at ambient temperature prior to getting washed with isopropyl alcohol (IPA) to eliminate any leftover wafer residue.

(B) The mold is filled with a 10:1 (weight) mixture of PDMS (liquid) and cross-linking agent (to cure the PDMS) and heated to a high temperature. The PDMS can be removed from the mold once it has solidified. In the PDMS block, a micro-channel has now been created.

(C) The cooked PDMS channel was separated from the original, cut, and punched to join the micro-tube. PDMS devices were directly bonded to a glass substrate without any surface preparation and then treated with oxygen plasma. To enable fluid injection, the microfluidic device's inputs and outputs are punched with a PDMS puncher. Finally, plasma is used to treat the glass slide and the face of the PDMS block with microchannels. The microfluidic chip can now be sealed with PDMS and glass bonding thanks to the plasma treatment.

Fig. 3-a,b show the micro-scale channel embedded in PDMS polydimethylsiloxane to generate the flow. Dimensions of PDMS were $1 \mathrm{~cm}$ in length, $1 \mathrm{~cm}$ in width, and $0.5 \mathrm{~cm}$ in height.

For shear stress assay, the device was mounted on the stage of an upright microscope (Nikon L150) and the channel region was made visible with its $40 \mu \mathrm{l} /$ minute objective. Using Teflon-tubing, the outlet of the channel was connected to the syringe pump. Fluid flow was started in the channel by filling the micro-channel inlet with cell culture media and pumping at a high flow rate $(40 \mu \mathrm{l} /$ minute). In this paper, a syringe pump produces shear stress ranging from 15 to 45 dyne per square meter (the cell culture media were flushed by a syringe pump). Before and after the experiment, pictures were recorded and adhering cells were counted to get the residual fraction. Finally, as a function of shear stress intensity, the proportion of adhering cells was displayed. The critical shear stress, at which only $50 \%$ of the cells remained, was used to determine each cell's physical adhesion strength. According to the findings, there is no significant difference in physical resistance to shear stress between treated and untreated cells at gas flow rates between 1 and 1.2slm and culture-media flow rates between 15 and 45 dyne $/ \mathrm{m}^{2}$. The critical shear stresses of untreated and treated stem cells were measured as 25.42 and 25.57 , respectively. The student's t-test was used in statistical analysis and $\mathrm{p}<0.05$ was considered significant. All data were expressed as mean \pm SEM from at least three independent experiments, in which more than 580 cells were counted. Therefore, the amount of gas flow has no effect on cell separation in this range of the flow rate. 

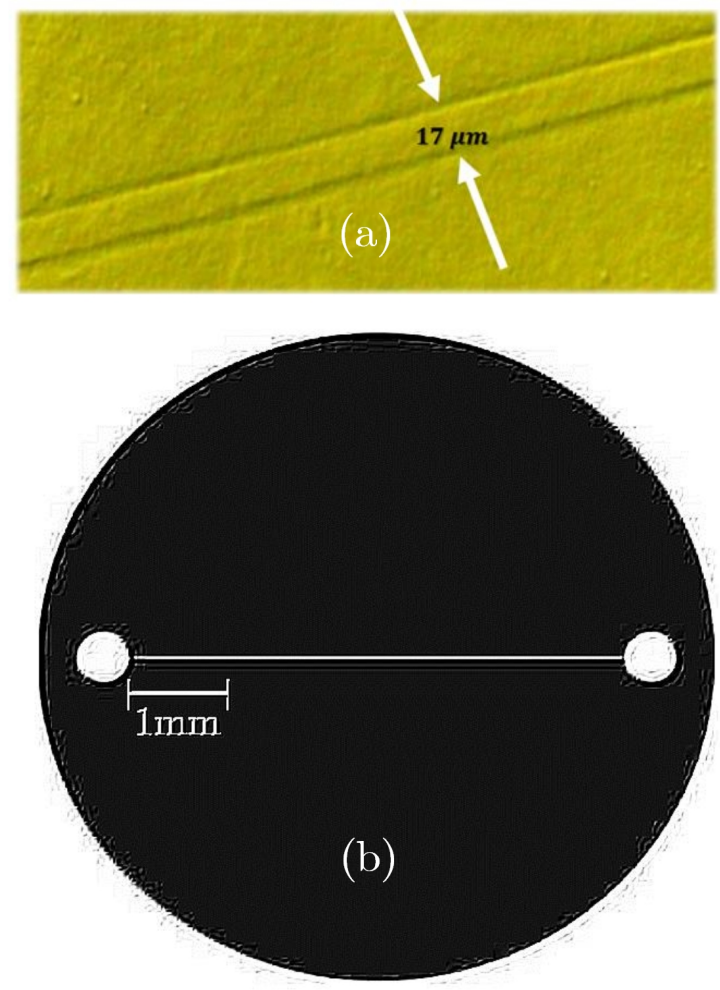

Figure 3: (a) Shear stress channel embedded in the polydimethylsiloxane, (b) Embedded 17-micron channel to create shear stress.

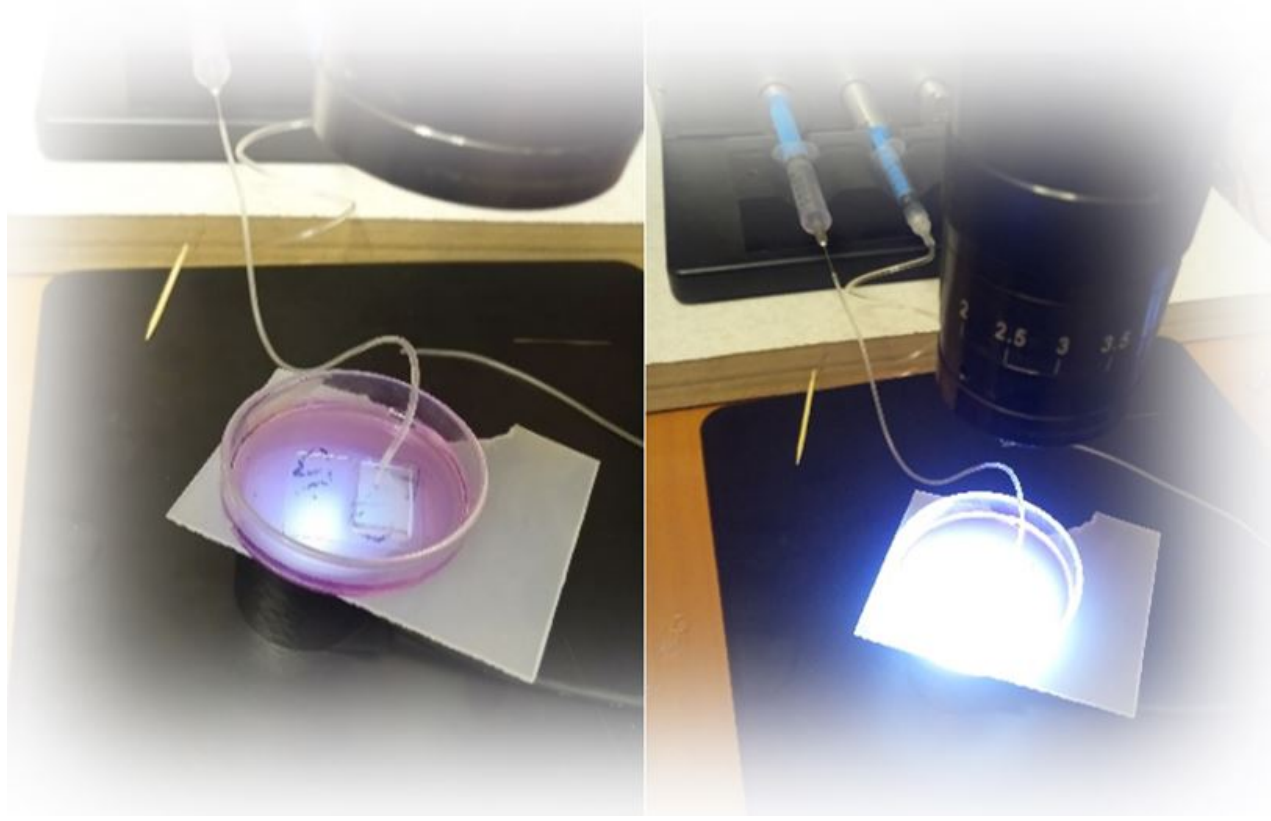

Figure 4: connecting the syringe pump to the micro-channel and making stress via the 17-micron channel in PDMS 


\section{Results}

\subsection{De-Adhesion Dynamics of Cells}

De-adhesion experiments were performed, according to Sen [40]. To this end, cell resistance to de-adhesion was evaluated, and the adhesion strength coefficient was determined. A schematic of de-adhesion assay can be seen in Fig 5-a. In summary, cells were seeded on coverslips, incubated for $24 \mathrm{~h}$, and then treated with plasma as described previously. At the next step, treated cells were washed with 1X PBS; afterward, mounted on the stage of a microscope. At the last step, they were incubated with $0.25 \%$ trypsin-EDTA, and images were recorded at a $15 \mathrm{~s}$ interval at 40x magnification until the cells were collected (rounded) but still remained attached to the substrate (with no further apparent change in the spread area). It indicates that the focal adhesions that anchor the cell to the culture plate or flask are cut away. The cell separated from the substrate by providing a very little strain. Figure 5-b shows the time-evolution process of cells during de-adhesion assay. Images were processed in NIH (National Institutes of Health-Laboratory). To determine the effect of plasma treatment on the de-adhesion time, at least 30 cells were examined in three independent experiments and repeated for both high- and low-dose conditions. Student's t-test and one-way ANOVA have been employed to determine the statistical validity of the results. $* \mathrm{P}$-and $* * \mathrm{P}$-values for each set of results are listed in the corresponding captions.

The cell detachment assay had two steps: First, Trypsin-EDTA utilized to detach focal adhesion contacts between cells and ECM. Next, cell contraction was observed until rounding up and separating from the substrate. In the meanwhile, images of both treated and non-treated cells were recorded every $15 \mathrm{~s}$ and analyzed with a canon microscope. The surface area of the cells was calculated in a time-dependent manner. The difference between the cell area in time $t$ and the initial one (i.e., $A_{\text {initial }}-A_{t}$ ) normalized to the difference between the initial and final cell surface (i.e., $A_{\text {initial }}-A_{\text {final }}$ ) were measured at each time.

\subsection{De-adhesion assay results}

The de-adhesion test approach Sen [40] was used to determine the defined normalized cell area for both treated and non-treated cells, and its plot vs. time is given in Fig. 6-a, b.

For more detailed quantitative investigations, we obtain two specific time constants, $\tau_{1}$, and $\tau_{2}$. The mean time constant of $\tau_{1}$ for control cells is, $\tau_{1} 131.2 \mathrm{~s}$, whereas it is $\tau_{1} 164 \mathrm{~s}$ for plasma-treated cells, indicating a statistically significant difference of $20 \%$. As can be seen the $\tau_{1}$ of treated cells is increased from 131 to 164. Moreover, the strength of adhesion shows a dose-dependent manner, see table 1 . The cell response was sigmoid, as predicted, and was divided into three distinct stages: early delay, fast cell contraction, and saturation platform. Fig. 6-a, b demonstrate some of the findings. The adhesion strength of treated cells increased in general as compared to non-treated cells. More importantly, a significant increase in adhesion occurred with high dosage treatment, indicating that adhesion increased in a dose-dependent manner. The control cells rounded in 131 seconds, 
Table 1: The time constant and saturation timeof cell axposed plasma with different generator powers, with: "Exposure Time: 60s, Gas Flow Rate: 1 slm, and Distance between plasma plumes tip and cell: $5 \mathrm{~mm}$ ". As findings imply, the time constant and saturation time increased with increasing plasma power. For comparison, both time constant and saturation time of a cell on a gel-coated plate are also listed in the last row.

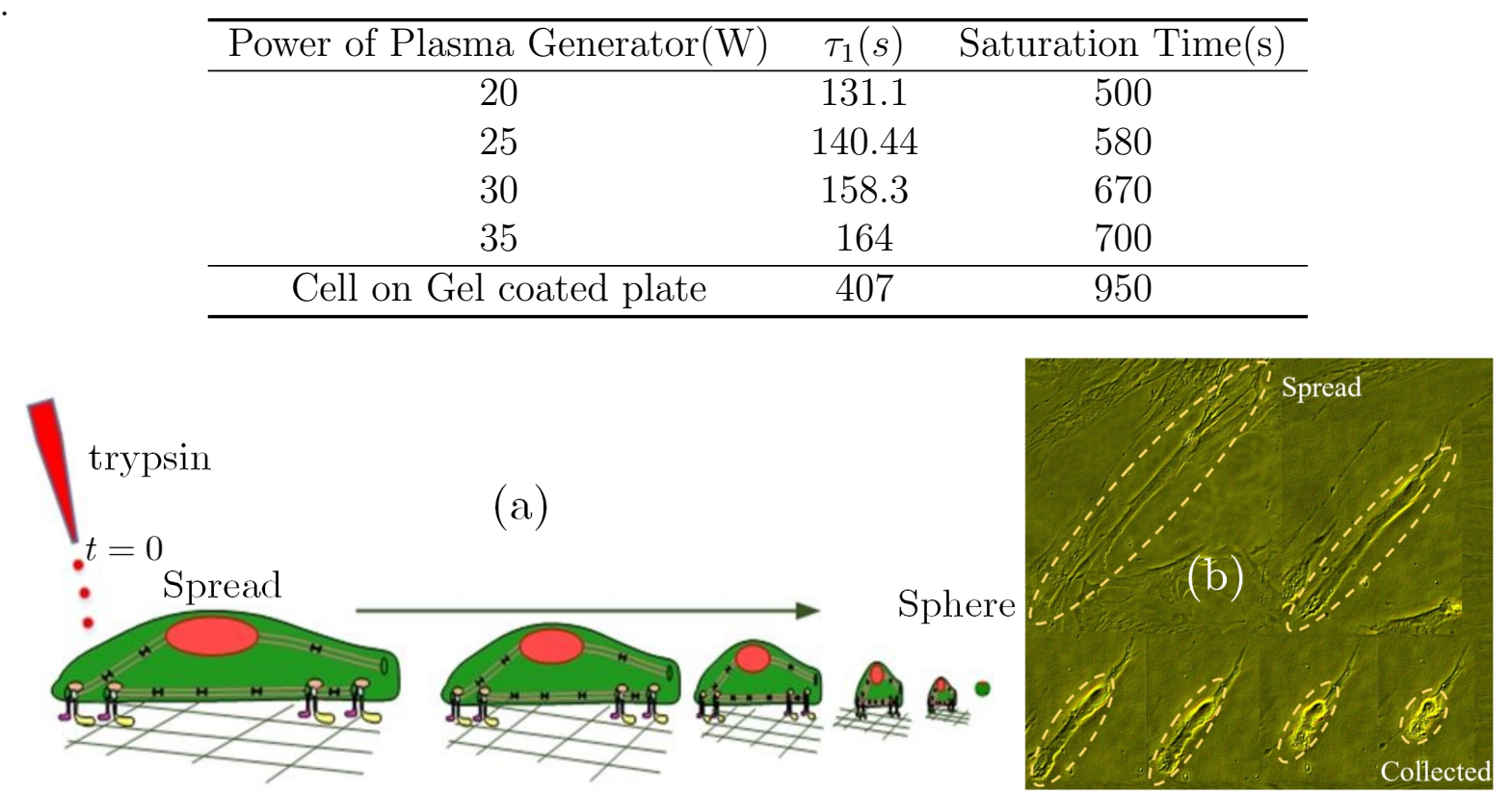

Figure 5: a) Schematic of de-adhesion assay b) changes in cell surface area before detachment.

whereas the plasma-treated cells took 164 seconds to aggregate, as can be seen in Fig. 6-a, b. As these figures show, the treated cells reached saturation levels in 700 seconds, while control cells reached saturation levels in 500 seconds.

Increasing the adhesion of the cells under plasma treatment was associated with the enhancement of the production and activity of integrin proteins, which leads to enhanced cell-substrate adhesion, as Weltmann, Haertel [32,33,42] and Keidar [36] demonstrated in separate papers. Although, unlike integrin, Cadherin (a protein involved in cell adhesion) shows no change after plasma treatment [43]. This means that this protein has not any role on the increasing the cell adhesion after plasma treatment.

\subsection{Focal Adhesion Assay}

According to the previous section, cell adhesion increased by 1.4 after plasma treatment. The increase in cell-focal adhesion was measured using a straightforward technique in 

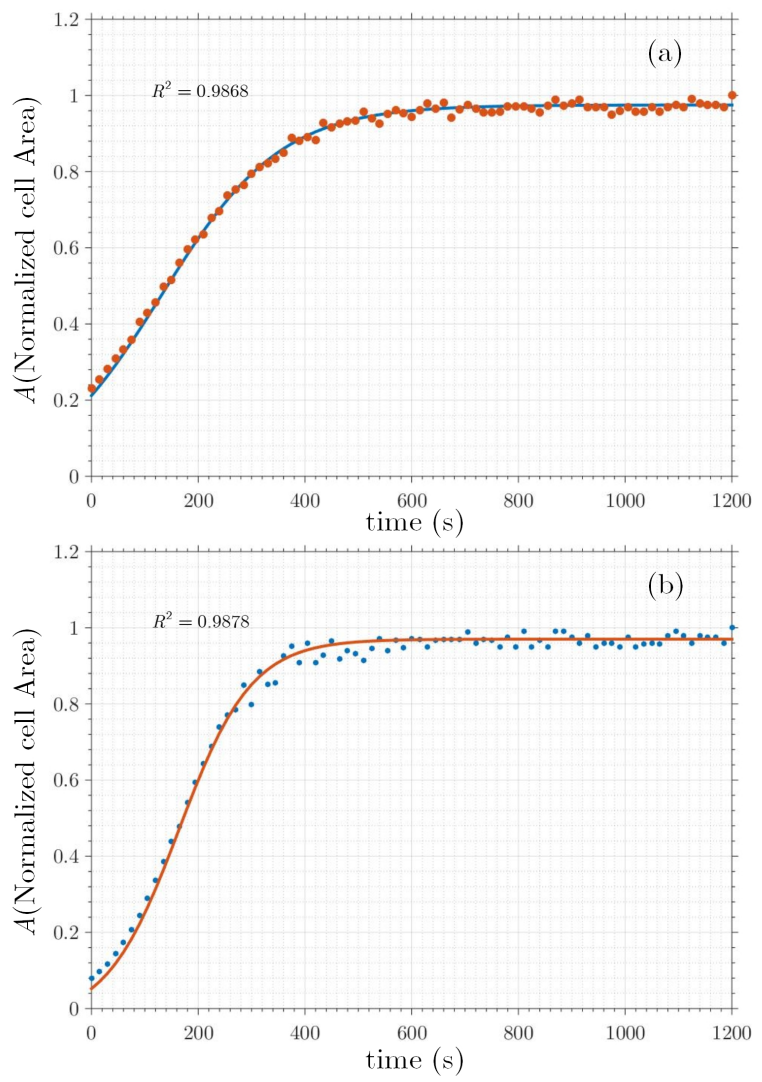

Figure 6: Cell Normalized Area vs. Time. From which Adhesion Coefficient and elasticity were inferred a) After treatment, b) Before treatment. 


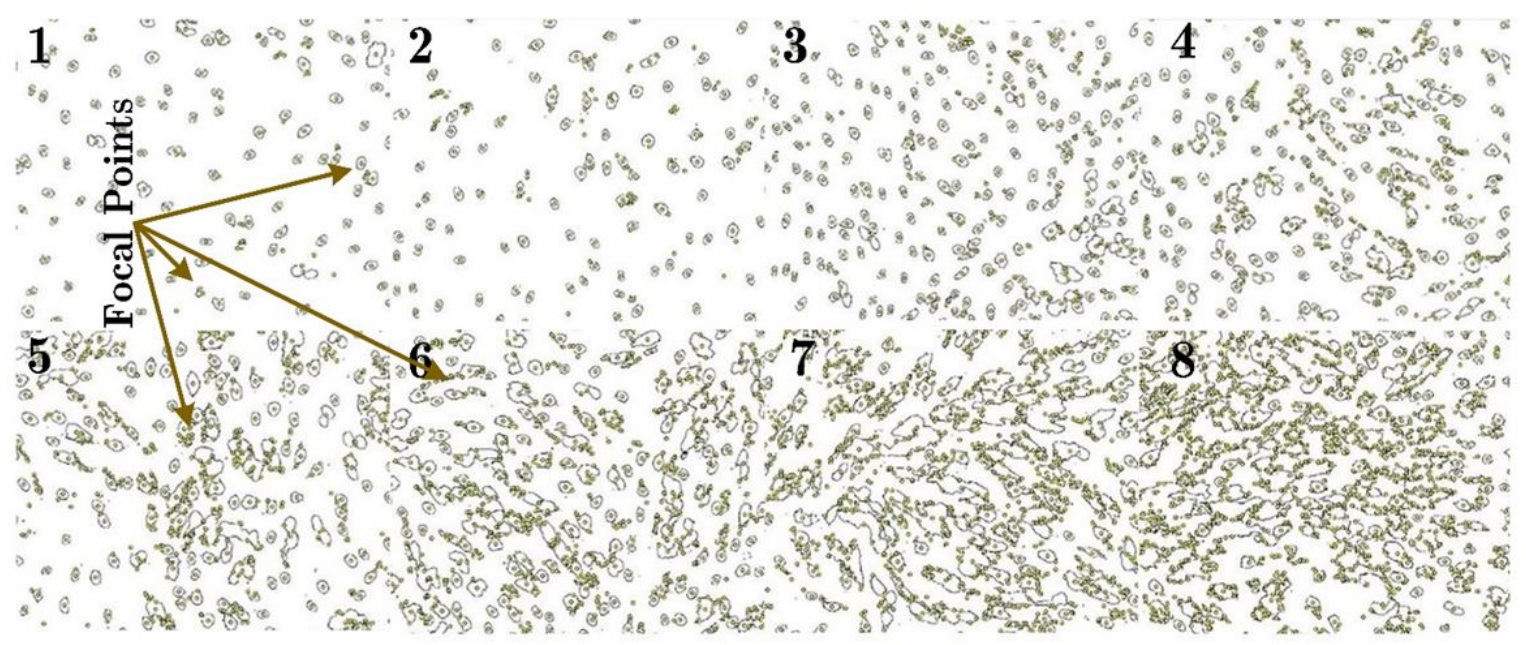

Figure 7: 1) before treatment and before FA formation, 2) cells treated with Argon (plasma-off) after the formation of FA, and from 3-8 the cells were directly exposed to plasma (power $=20 \mathrm{~W}$ ) for different exposure times: 3) $\mathrm{t}=30 \mathrm{~s}, 4) \mathrm{t}=50 \mathrm{~s}, 5) \mathrm{t}=70 \mathrm{~s}, 6$ ) $\mathrm{t}=90 \mathrm{~s}, 7) \mathrm{t}=100 \mathrm{~s}, 8) \mathrm{t}=120 \mathrm{~s}$. As can be seen in $3-8$, more focal points are formed. Increase in FA points depends on the exposure time.

this study. To compare FA formation before and after plasma treatment, stem cells were exposed to plasma at varied time duration (30-120s). The plasma generator had a $20 \mathrm{~W}$ output. Control groups consisted of two groups of four. As soon as the cells attached to the plate, but before FA production, the first group was stained with DAPI (according to Sigma-Aldrich cell staining protocols). The other group was treated with Argon while the plasma was off. The cells were all stained with DAPI (same protocol) and their images were recorded. Counting the focal points became possible after converting the images to an 8-bit format and subtracting background by combining CLAHE and LOG-3D filter plugins. Use has been made of NIH to count the focal points. The results, shown in Fig. 7 , confirmed the increase in focal points in a dose-dependent manner during the plasma exposure. When the exposure time was between 70 and 120s, the focal points increased by 1.3-1.7, respectively, which is consistent with the results of the previous section.

Like the de-adhesion analysis, this increasing of the focal cell-ECM adhesion after plasma treatment could be related to enhancement of the production and activity of integrin proteins.

\subsection{Cell-Cell Adhesion Strength}

Up to now, both previous experiments were associated with an increase in cell-ECM adhesion after plasma treatment due to enhancement of the production and activity of integrin proteins. So, another experiment is required to evaluate the effect of cold plasma on the change in cell-cell adhesion, such that the increase in integrin expression and activation does not affect the results. To this end, current study offers an experiment based on the technique outlined by Kendall and Roberts [23]. In this approach, to get rid of the integrin expression on the adhesion strength, experiments could be repeat for the 


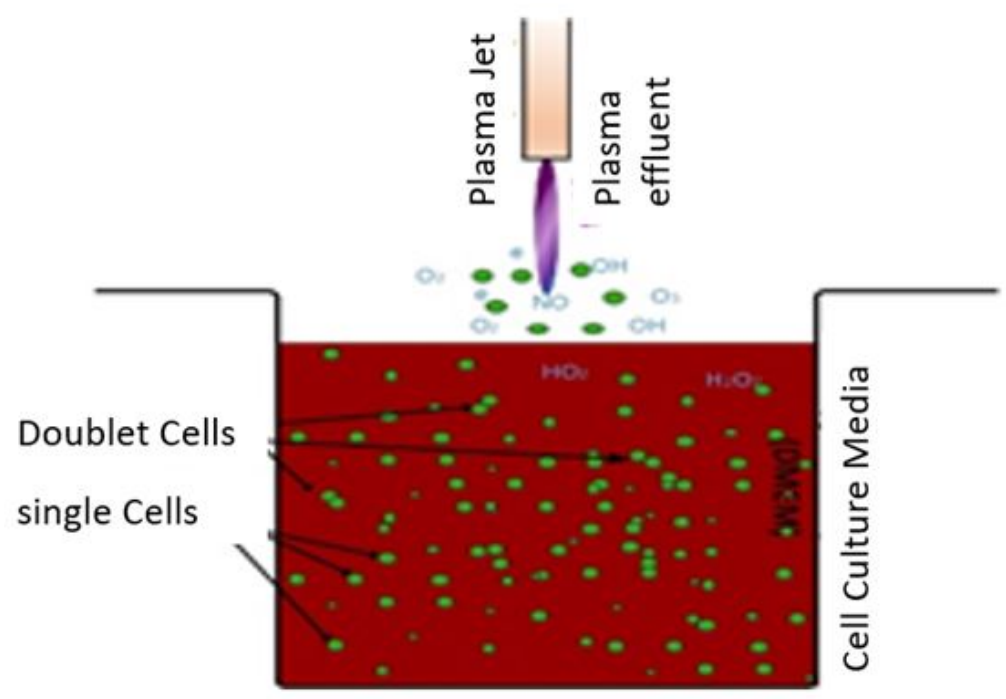

Figure 8: The schematic of plasma-treated cells in cell-suspension.

Table 2: The ratio of doublets to singles before and after treatment. As can be seen, this ratio increases after treatment, the longer the exposure time, the higher the ratio.

\begin{tabular}{ccccccccc}
\hline & Control & Plasma-off & $t=30 \mathrm{~s}$ & $t=50 \mathrm{~s}$ & $t=70 \mathrm{~s}$ & $t=90 \mathrm{~s}$ & $t=100 \mathrm{~s}$ & $t=120 \mathrm{~s}$ \\
\hline Mean of $N_{2} / N_{1}$ & 0.097 & 0.113 & 0.318 & 0.400 & 0.509 & 0.581 & 0.597 & 0.648 \\
\hline
\end{tabular}

case in which cells are removed from the substrate to create a cell suspension. We claim that, in this scenario, the probable rising of the adhesion cell, if it's seen, could be related to the increasing of Van der Waals (VDW) force rather than integrin production and activation $[23,26]$. Additional dipoles form when the cell is exposed to plasma, leading in an increase in VDW force.

To evaluate cell-cell adhesion strength before and after plasma treatment, cells were treated with trypsin, collected in separate vials, and trypsin was inactivated by adding Trypsin Neutralization Solution (TNS). Two controls are adopted in this experiment. One was not exposed to gas nor plasma, while the other was treated solely with argon with no plasma ignition, see Fig. 9- 1, 2. For the treated cases, the power was set at $20 \mathrm{~W}$ as the low-risk level [37] and the gas flow rate set to 1slm. Each vial was then exposed to plasma for various time intervals (30-120s), as shown in Fig. 8. After treatment, the cells of each vial were seeded on different slides to facilitate the imaging process. They were stained with DAPI according to cell staining protocols, and their images were recorded.

As shown in Fig. 9 (3-8) as well as in table 2, the ratio of doublet to singlet increased when the cells were exposed to plasma. This ratio is larger for longer exposure times, as can be shown. Therefore, it can be inferred that following treatment, cell-cell adhesion 


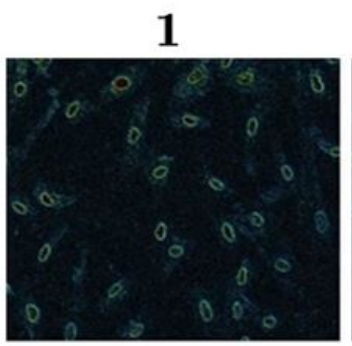

5

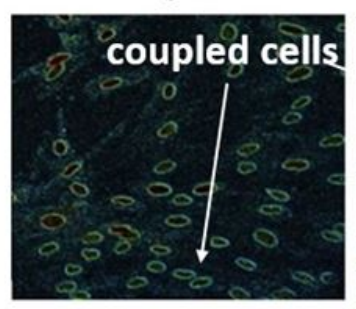

2

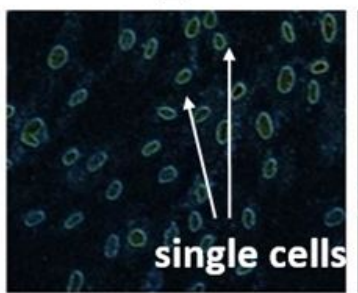

6

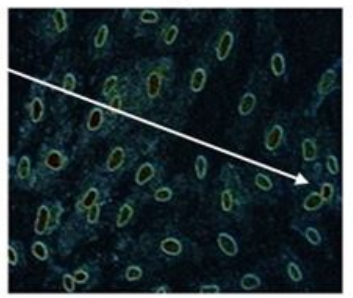

3

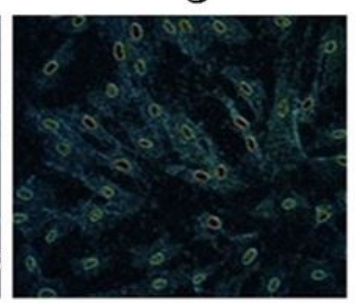

7

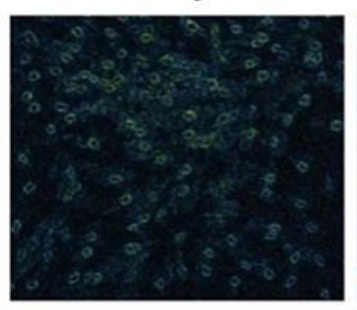

4

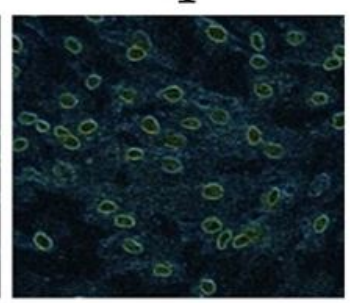

8

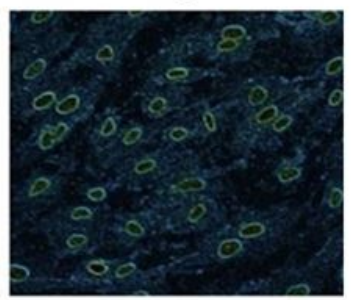

Figure 9: 1) before treatment, 2) cells treated with Argon (plasma-off). Almost all cells are single. For 3-8, cells were directly exposed to plasma (power $=20 \mathrm{~W}$ ) with different exposure times: 3) $\mathrm{t}=30 \mathrm{~s}, 4) \mathrm{t}=50 \mathrm{~s}, 5) \mathrm{t}=70 \mathrm{~s}, 6) \mathrm{t}=90 \mathrm{~s}, 7) \mathrm{t}=100 \mathrm{~s}, 8) \mathrm{t}=120 \mathrm{~s}$. As can be seen in 3-8, more couples are formed after treatment and the number of couples increases depending on the exposure time.

increased. The increase in cell adhesion could be a consequence of the increase in VDW force between cell-cell.

Given that the number of cells sticking to each other following plasma exposure is significantly larger than single cells, the ratio of binary cells to single cells in terms of cell volume percentage could be a straight line passing through the origin which gradient of that is the adhesion strength. To explain that, we borrow a theoretical formula by Stainton [23] to predict the number of doublets that would form in a cell suspension after treatment. Sainton showed that the ratio of doublets to singles, $N_{2} / N_{1}$, is proportional to the volume fraction $\varphi$ of cells as

$$
\frac{N N_{2}}{N_{1}}=4 \varphi\left(\lambda^{3}-1\right) \exp \left(\frac{\varepsilon}{k T}\right) \approx \frac{N_{2}}{N_{1}}
$$

where $\lambda$ and $\varepsilon$ are the potential well parameters, $\varphi$ is the cell fraction volume, and $N$ is the total number of cells. Therefore, the graph of the $N_{2} / N_{1}$ versus cell volume fraction should be a straight line passing through the origin. The slope of this line is the adhesion-resistance coefficient [23].

\section{Discussion}

As been explained in the results section, the role of the plasma on the cell-ECM adhesion and the cell-cell adhesion strengths have been investigated in the different experiment set-ups by employing the de-adhesion assay and focal adhesion analysis. Analyzing the cell-ECM adhesion for the plasma treated and untreated cases show that the cell-ECM adhesion increases for the plasma treated cases by the dose and the time exposure attributed to the enhancement of the production and activity of the integrin protein in the 
medium. Studying the plasma role on the cell-cell adhesion by ignoring the activation of the integrin protein by creating a suspension shows that plasma increases the cell-cell adhesion with increasing the number of coupled cells in comparison to untreated cases. To find the physical reason of this observation, it should be considered that the cell surface is the first part to be exposed to the plasma-induced electric field and RONS. The cell wall itself contains large amounts of polysaccharides and other natural polymers. As a result, positive ions are adsorbed from the media to the surface $[44,45]$. Carstensen et al. Showed that the cell wall is actually an ion exchanger [46,47]. In fact, charged groups on the cell wall exchange small molecules with the environment [45,48]. Therefore, it is expected that the electrical properties of the wall will change with the concentration of ions in the environment [48]. In plasma-exposed media, a large number of ions are generated, which might change the charge distribution in this area. Although the conductivity of the cell wall remains constant at low ion concentrations, it rapidly rises as the ion concentration increases $[46,47]$. Consequently, the presence of plasma ions alters the electrical properties of the wall, including its conductivity and permittivity. The dielectric constant of any substance is affected by the polarization of the molecules. In the case of non-polar molecules, polarizability results from electronic polarization, that is, an electron is shifted relative to the nucleus. Accordingly, to comprehensively study the effect of plasma-induced fields, with the source frequency in the $\mathrm{MHz}$ range (as in our case), the rate of increase in plasma-induced dipole formation as well as electrical conductivity, the dielectric permittivity of the cell wall, and dielectric permittivity of the surrounding aqueous media must be taken into account. All of these parameters have major roles on the intercellular van der Waals force as a key phenomenon in increasing the cell-cell adhesion after plasma treatment. In the next section, a theoretical model is adopted to demonstrate the effect of each of the parameters involved in plasma therapy, including electromagnetic waves and charged species, on the intercellular van der Waals force. In this regard, the role of these parameters on the dipole creation and changing the dielectric constant of the culture medium, attributed on the Hammaker coefficient modification, will be investigated semi-empirically.

\section{Dipole Formation (van der Waals Force)}

At the previous section, it was discovered experimentally that exposing a cell to plasma increases the cell-cell adhesion. Generally speaking, according to Curtis [49], the state of the plasma-lemma lipids, which is influenced by physical plasma, affects cell adhesion. These effects can be explained either in terms of the van der Waals, VDW, forces or changes in surface fluidity, both of which are influenced by cold atmospheric plasma. Therefore, to study the plasma-induced cell-adhesion changes, the VDW forces must be considered before and after plasma treatment. The VDW force, an ever-present force among all molecules, plays a valuable role in cell adhesion. VDW force caused by the fluctuation of electric dipole-moment of molecules is a ubiquitous force between two molecules. Here, charge fluctuations occur for two reasons: 1) The presence of a plasma-induced electric field, 2) The proximity of two molecules with a total zero charge. This force has a meaningful influence on various phenomena, including cell adhesion, metastasis, and fusion [26].

Putting an isotropic particle in a homogeneous environment with a uniform electric 


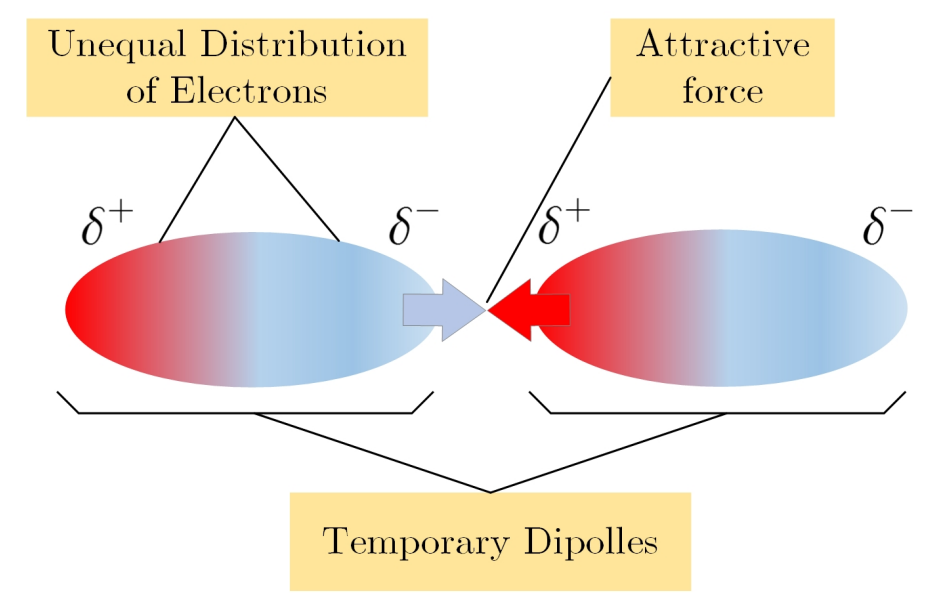

Figure 10: A schematic of the VDW force between temporary dipoles.

field, the electric field surrounding the particle is disrupted [37]. Charge separation occurs at the particle's surface as a result of the electric field, leading in the production of transitory electric dipoles. A similar scenario might occur when a cell is exposed to atmospheric plasma, as shown schematically in Fig. 10. That is, the Plasma-induced electric field can form temporary dipoles. In this section, we will present a theoretical model to obtain the dipole moment of a plasma exposed cell, and look at how the VDW force changes between cell-cell when they are exposed to an RF-plasma (only exposed electromagnetic fields effect). It is worth noting that the plasma role on the changes on the VDW force between the cells are not only due to creation of electrical dipoles but it also modifies the medias dielectric constant which in turn changes the Hammaker coefficient (see, Eqs. 18, 19), as a key parameter in VDW force strength between the cells. So, the effect of the charged plasma species on the Hammaker coefficient also will be semi-empirically examined as a part of this section. Finally, the role of the presence of charged plasma species on the dipole formation will be studied at the end of this section.

\subsection{Exposed Electromagnetic field effect on VDW force (dipoles creation)}

Regarding the fact that most human cells are spherical with a radius of 10 to $100 \mu \mathrm{m}$, the size of a human cell and the wavelength of the exposed electromagnetic wave are comparable as long as the frequency is about $10 \mathrm{THz}$. As a result, the quasi-static approximation could be used for the frequencies of relevance in this work, $13.56 \mathrm{MHz}$. To figure out the solution of the electric field, use has been made of the Maxwell's Equations and considering that $\nabla \times \nabla \Psi=0$ for all $\Psi$, the electric field can be written in terms of the scalar potential of $\varphi(r)$ :

$$
E(r)=-\nabla \varphi(r) .
$$

At the first approximation, without considering the role of the charged plasma species 


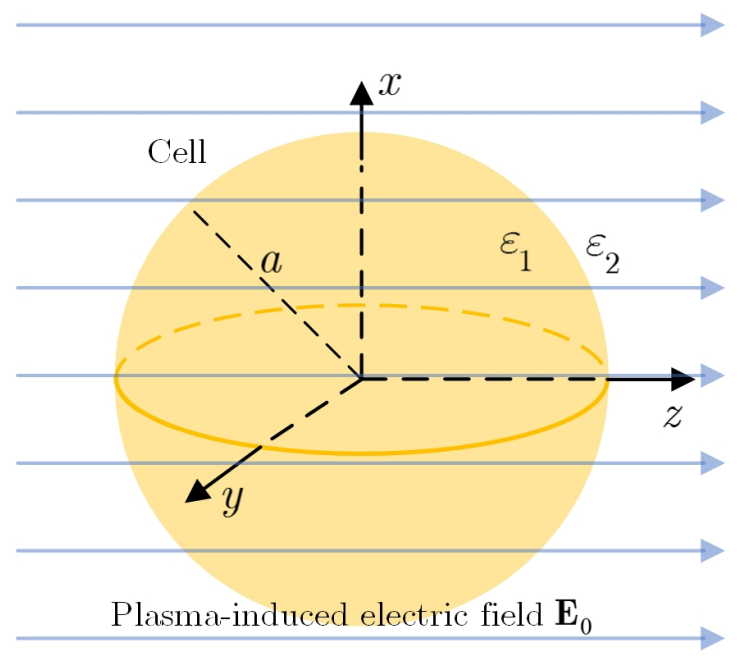

Figure 11: Plasma-induced electric field, $\mathbf{E}_{0}$, applied to a spherical cell with no organelles, the radius of cell is $a$.

in the medium on one hand and using the assumption of $\rho=0$ for biological cells in the scale under study on other hand, we can write Laplace equation as:

$$
\nabla^{2} \varphi(r)=0
$$

Laplace Equation is solved by considering a cell as a dielectric sphere of radius $a$ with its center at the origin of the coordinates and a constant and uniform electric field in $z$-direction, $\mathbf{E}_{0}=E_{0} \hat{z}$, see Fig. 11. The solution is:

$$
\Phi(r, \theta, \varphi)=\frac{U(r)}{r} P(\theta) Q(\varphi)
$$

According to Eq. 2, the incident potential is:

$$
\Phi(r)=-E_{0} z
$$

Therefore,

$$
\Phi(r)=-E_{0} r \cos \varphi=-E_{0} r P_{1}(\cos \theta),
$$

here $P_{1}(\cos \theta)$ is the Legendre polynomial of order $n=1$. Therefore, the total potential outside of the cell is $\Phi(r, \theta)=\Phi_{0}(r, \theta)$.

In this equation, the electric potential at infinity must be equal to the initial potential and also, as a good assumption, the electric potential at the origin of the coordinates could be limited due to lack of charge inside the cell.

Accordingly, we can write:

$$
\Phi_{\mathrm{in}}(r, \theta)=\sum_{n=0}^{\infty} A_{n} r^{n} P_{n}(\cos \theta),
$$


and

$$
\Phi_{\text {out }}(r, \theta)=\sum_{n=0}^{\infty} B_{n} r^{-(n+1)} P_{n}(\cos \theta)-E_{0} r P_{1}(\cos \theta) .
$$

By applying the boundary conditions such that the electric potential at the cell surface is continuous $\Phi_{\text {in }}(r=a, \theta)=\Phi_{\text {out }}(r=a, \theta)$, and the vertical component of the flux density is constant, we will have:

$$
\begin{aligned}
& -E_{0} r P_{1}(\cos \theta)=\sum_{n=0}^{\infty}\left[A_{n} r^{n}+B_{n} r^{-(n+1)}\right] P_{n}(\cos \theta), \\
& -\varepsilon_{0} E_{0} a P_{1}(\cos \theta)=\sum_{n=0}^{\infty}\left[\varepsilon_{1} A_{n} n r^{n-1}+\varepsilon_{2} B_{n}(n+2) r^{-(n+2)}\right] P_{n}(\cos \theta) .
\end{aligned}
$$

Considering that the Legendre polynomials are orthogonal, the terms in the right-hand side of Eqs. 9 and 10 are eliminated and only $n=1$ is not vanished. Accordingly:

$$
\begin{aligned}
& \Phi_{\text {in }}(r, \theta)=-\frac{3 \varepsilon_{1}}{\varepsilon_{1}+2 \varepsilon_{2}} E_{0} r \cos \theta \\
& \Phi_{\text {out }}(r, \theta)=-\frac{\varepsilon_{1}-\varepsilon_{2}}{\varepsilon_{1}+2 \varepsilon_{2}} E_{0} \frac{a^{3}}{r^{2}} \cos \theta-E_{0} r \cos \theta
\end{aligned}
$$

Making use of Eq. 2, the electric field can be obtained from Eq. 11 by changing the coordinates to rectangular. So we will have:

$$
\mathbf{E}_{\text {in }}(r, \theta)=\frac{3 \varepsilon_{1}}{\varepsilon_{1}+2 \varepsilon_{2}} E_{0} \hat{z}
$$

the cell is an electric dipole of which its moment can be interpreted as the volume integral of the polarization $\mathbf{P}$, therefore,

$$
P=\left(\varepsilon_{1}-\varepsilon_{2}\right) E=3 \varepsilon_{1} \frac{\varepsilon_{1}-\varepsilon_{2}}{\varepsilon_{1}+2 \varepsilon_{2}} E_{0},
$$

and hence the dipole moment is:

$$
\mathbf{P}=4 \pi \varepsilon_{1}\left(\frac{\varepsilon_{1}-\varepsilon_{2}}{\varepsilon_{1}+2 \varepsilon_{2}}\right) a^{3} E_{0} \hat{z}
$$

Consequently, the cell behaves as an electrical dipole with the dipole moment of Eq. 15. Thus, two close cells behave like a dipole which is shown in Fig. 10 schematically. Subsequently, the VDW force will change between cells, interpreted by Equation 4. 


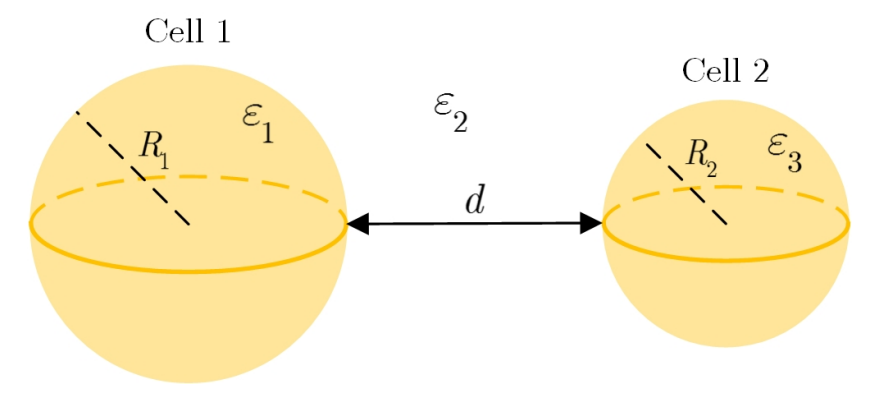

Figure 12: The Schematic of cells, their distance, media and their permitivities.

\section{2 charged plasma species effect on VDW force}

At the previous sub-section, the role of the exposed electromagnetic field in plasma therapy had been investigated on creation of dipole in the culture medium and so on VDW force between the cells related to cell-cell adhesion. At this part, the role of the delivered charge in the medium during the plasma therapy will be investigated on the VDW force between the cell and so on the cell-cell adhesion.

To this end, the cells are considered as sphere with no organelles inside, for simplicity. Therefore, the VDW energy of interaction depends on the surface geometry. For two spherical objects it is expressed as:

$$
G=-\frac{A}{6 d}\left(\frac{R_{1} R_{2}}{R_{1}+R_{2}}\right)
$$

Where $d$ is the separation of two cells, $A$ is Hammaker coefficient, and $R_{1}$ and $R_{2}$ are the radius of two cells which are assumed equal in this study (see Fig. 12). Therefore, $G$ can be written as:

$$
G=-\frac{A}{6 d}\left(\frac{R_{1}^{2}}{2 R_{1}}\right)=-\frac{A}{6 d}\left(\frac{R_{1}}{2}\right)
$$

According to Hammaker (1937), A is given by:

$$
A=\frac{3}{4} k T \frac{\left(\varepsilon_{1}-\varepsilon_{2}\right)\left(\varepsilon_{3}-\varepsilon_{2}\right)}{\left(\varepsilon_{1}+\varepsilon_{2}\right)\left(\varepsilon_{3}+\varepsilon_{2}\right)}
$$

in which $k$ is Boltzmann constant, $T$ is the temperature, and $\varepsilon_{1}, \varepsilon_{3}$, and $\varepsilon_{2}$ are the dielectric constants of cell 1 , cell 2 , and the cell culture medium, respectively. In this study $\varepsilon_{3}=\varepsilon_{1}$, therefore:

$$
A=\frac{3}{4} k T \frac{\left(\varepsilon_{1}-\varepsilon_{2}\right)^{2}}{\left(\varepsilon_{1}+\varepsilon_{2}\right)^{2}} .
$$

The VDWF is:

$$
G=-\frac{A}{6 D^{2}}\left(\frac{R_{1}}{2}\right) .
$$


a

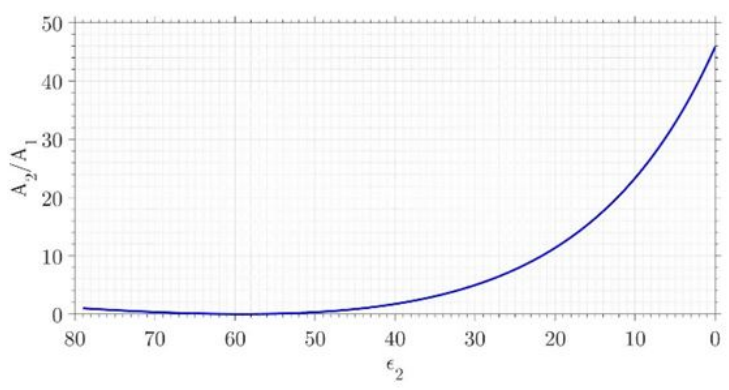

b

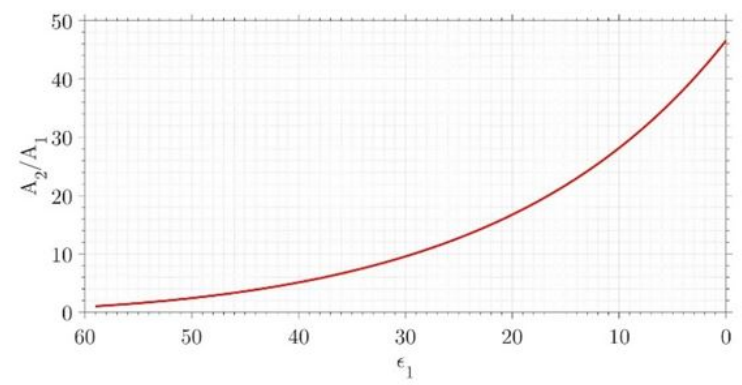

Figure 13: The ratio of $A_{2} / A_{1}$ increases by reduction in a) media permittivity, b) cell permittivity.

So, to find the effect of the delivered charge in the plasma therapy on the VDW force between the cells, we have to follow the change of the Hammaker Coefficient due to presence of these species in the culture medium. When cells and culture media are exposed to the plasma their electrical conductivity changes, as a result of the conductivity modification. In this sense, the relative electrical permittivity, $\varepsilon_{1}$, $\varepsilon_{2}$, will also change and eventually, it results in a change in Hammaker coefficient. Considering the water and cell wall permittivity, in Eq. 19, for example 80 and 60, respectively, it is found that a $2 \%$ decrease in the permittivity of the cell wall leads to a rise of $13.4 \%$ in the Hammaker coefficient, provided that the permittivity of the aquatic media remains constant. A further decrease in the permittivity of this wall leads to a sharp increase of $84.5 \%$ in the Hammaker coefficient. On the other hand, if the permittivity of the aqueous media surrounding the cell reduces by $40 \%$, the Hammaker coefficient significantly increases, 19.6-times.

In Fig. 13-a, b, the parameter $A_{2} / A_{1}\left(A_{1}\right.$ and $A_{2}$ are the Hammaker coefficients before and after treatment, respectively) vs. the value of the media permittivity and cell-wall permittivity has been illustrated, respectively. As can be seen in this figure, when the permittivity of the cell-wall decreases the ratio $A_{2} / A_{1}$ increases significantly. On the other hand, by reducing the permittivity of the media, until the permittivity of the media is $40 \%$ of its initial value after that, this ratio increases significantly. Regarding the fact that the VDW force directly depends on the Hammaker coefficient, an increase in this coefficient causes a rise in the VDW force. To determine the changes in Hammaker coefficient during the plasma therapy, $A$, the conductivity of the media is determined empirically by using a portable conductivity meter, shown schematically in Fig. 14. To this end, 6 vessels holding deionized water were exposed to plasma at different exposure times (between 30 and 120s). Then the conductivity of the media was determined by a Fisher-brand Traceable Conductivity-Meter and the results has been depicted in Fig. 15. As can be seen in this figure, the conductivity of PAW increases dramatically by adding the charged plasma species to the medium during the plasma therapy. 


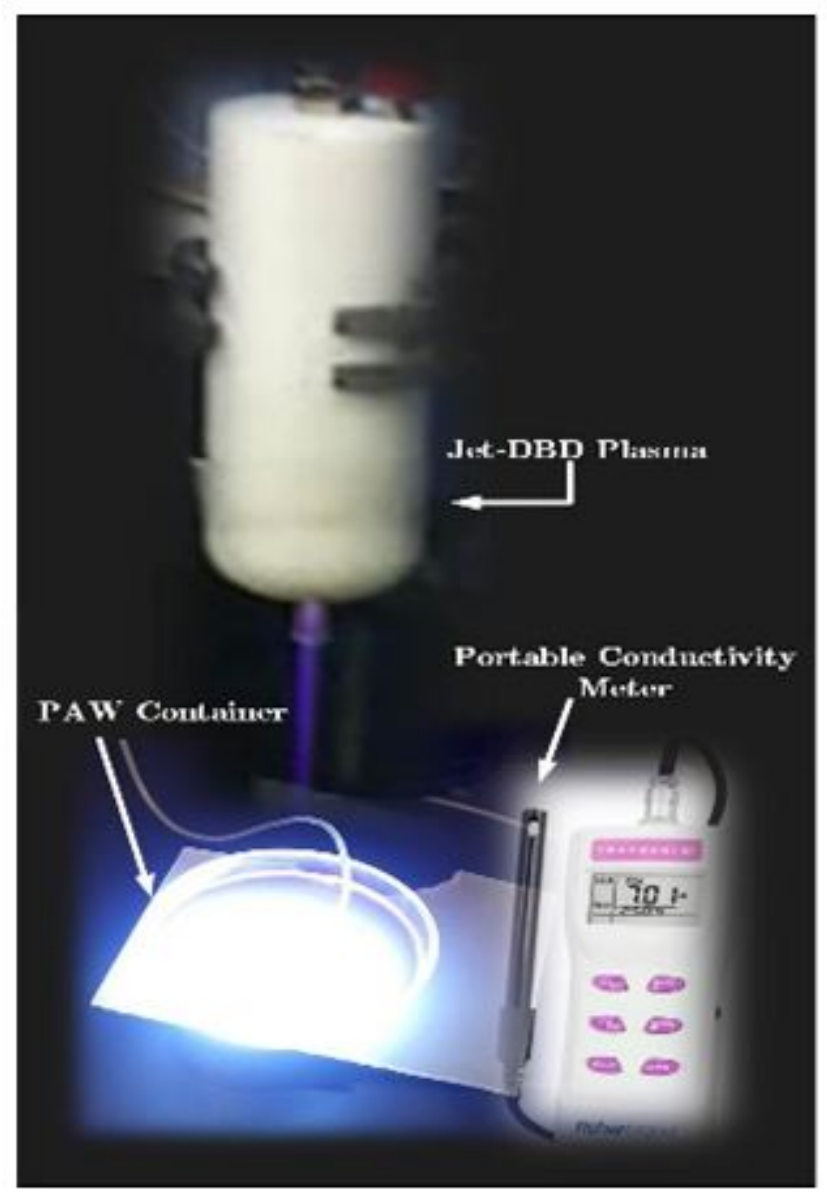

Figure 14: Schematic of determining the conductivity of plasma-exposed media by a portable conductivity-meter.

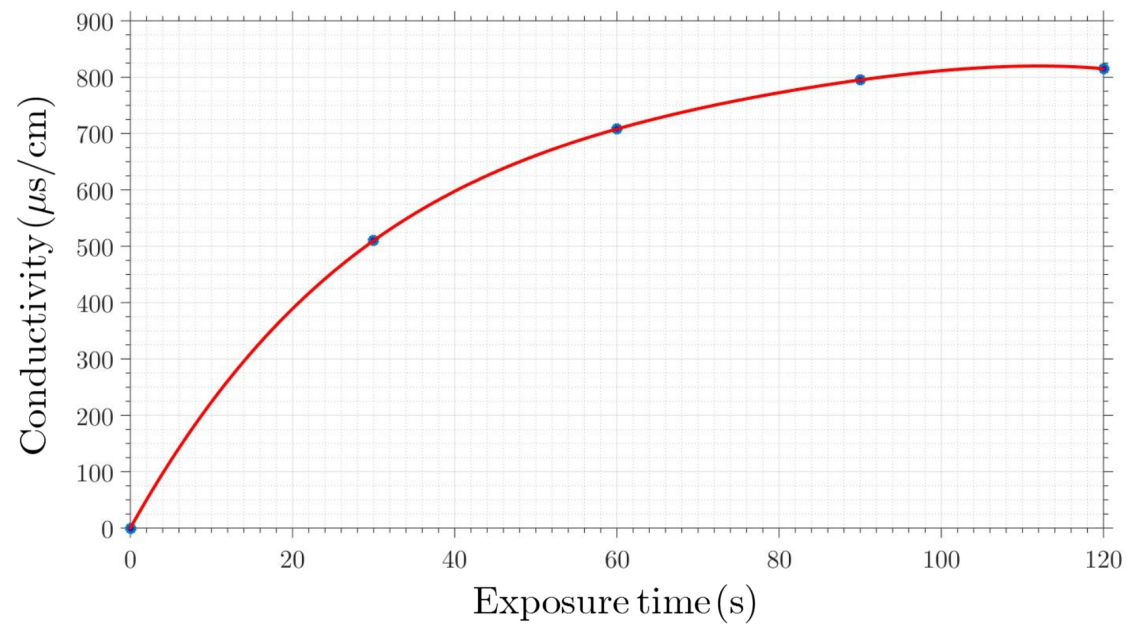

Figure 15: conductivity of medium vs. the plasma exposure time. 
The electrical conductivity can provide information on concentration of ions present in aqueous media. As can be seen in Fig. 15, electrical conductivity increases from $0 \pm 10 \mu \mathrm{S} / \mathrm{cm}$ to $723 \pm 10 \mu \mathrm{S} / \mathrm{cm}$ for the first 60 seconds plasma treatment, then it reaches to a saturation plateau from $60-120$ s exposure time. Linear regression of the first part gives following equation $\left(R_{2}=0.99\right)$ :

$$
\sigma=591.20+4.74 \tau \text {. }
$$

Variation of $\sigma_{\mathrm{PWA}}$ results from charged species production and consumption mechanisms occurring in the liquid phase, resulted from a complex interaction between the plasma and liquid phase which includes; a) the diffusion of gaseous species from the plasma to the liquid bulk, b) the stimulation of the liquid interface giving rise to new species in the sub-interface layer and then to their in-depth diffusion and, c) PAW heating effect induced by the plasma source.

At the last step, we try to find the charged plasma species effect on the dipole formation. How electrical charge is distributed near the cell membrane is the key to many of the problems associated with cells interacting with external electric fields. Many papers have investigated the spatial distribution of charge near the surface of biological membranes. The permittivity of the cell in an aqueous media relates to media permittivity by Maxwellequation.

Since the generation of a dipole in a cell at a given frequency depends on the conductivity of the surrounding medium, the increase in the conductivity affects polarization too. Considering Eq. 15, the term in bracket will be changed by conductivity modification as:

$$
P(z) \propto\left(\frac{\varepsilon_{1}-\varepsilon_{2}}{\varepsilon_{1}+2 \varepsilon_{2}}\right),
$$

As shown in Fig. 16, as it was expected, the decrement of permittivity of the cell wall results in enhancing of the dipole moment.

Due to the slight changes in the temperature of the exposed culture media, the dielectric constant dependence on temperature is not considered in the theoretical model. Another parameter affecting the VDW force is the cell's surface-roughness. The smoother the cell surface, the higher the VDW force [26]. Moreover, reducing the surface roughness decreases the closest-distance between the cells and so, the cells get closer to each other to experience the higher VDW force. The qualitative study of the plasma therapy effect on the VDW force between the cells (equivalently, cell-cell adhesion) through changing the cell roughness has been investigated empirically at the next section.

\section{Cell Roughness}

The roughness of cell surface can also affect the VDW force. In this regard, we used AFM (Atomic Force Microscope) images to evaluate the changes in cell roughness after plasma treatment. The images of cell roughness before and after treatment, Figures 17-a, b, show a softer cell surface after treatment. 


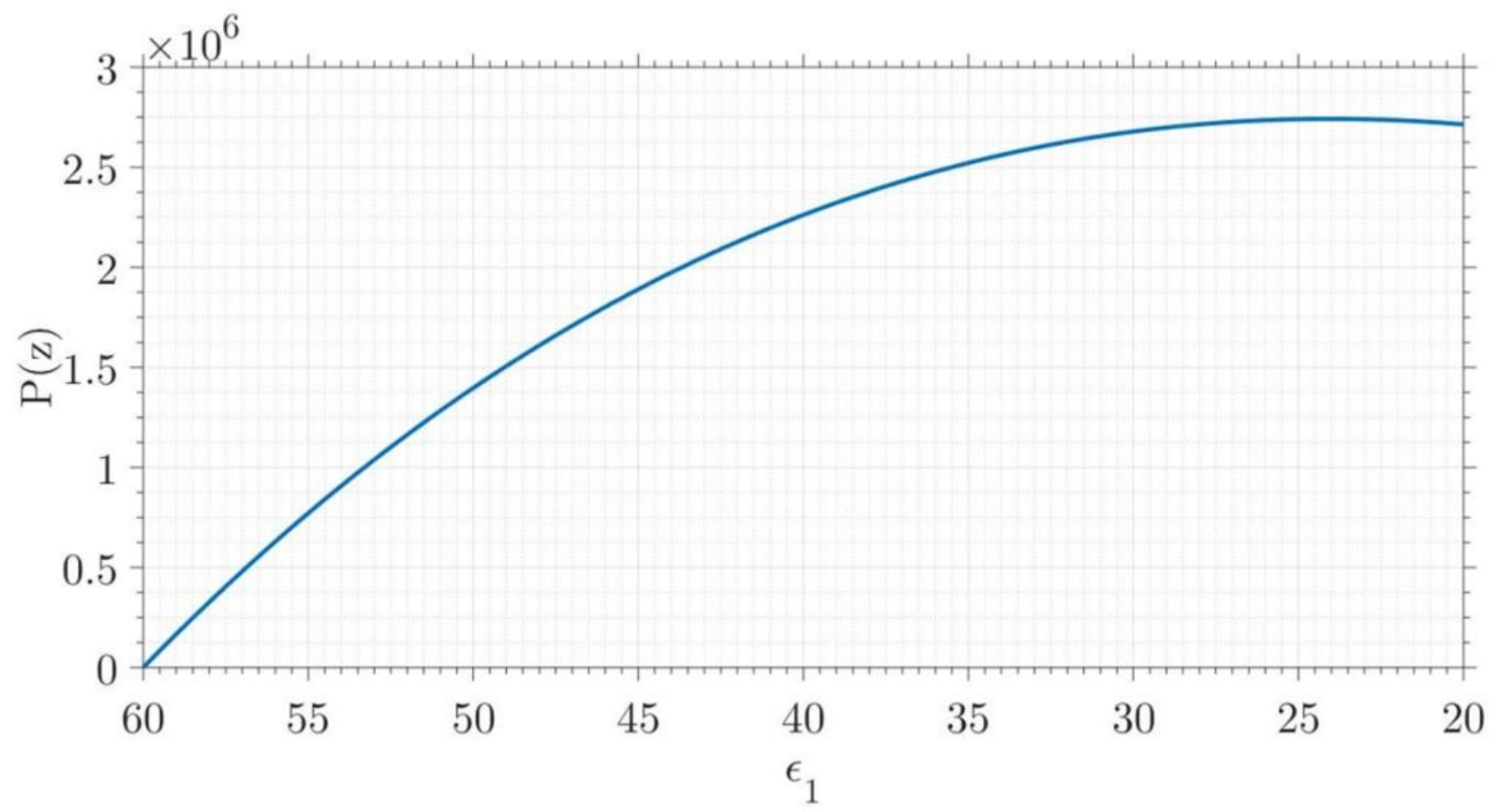

Figure 16: polarization moment vs. the permittivity of the cells.
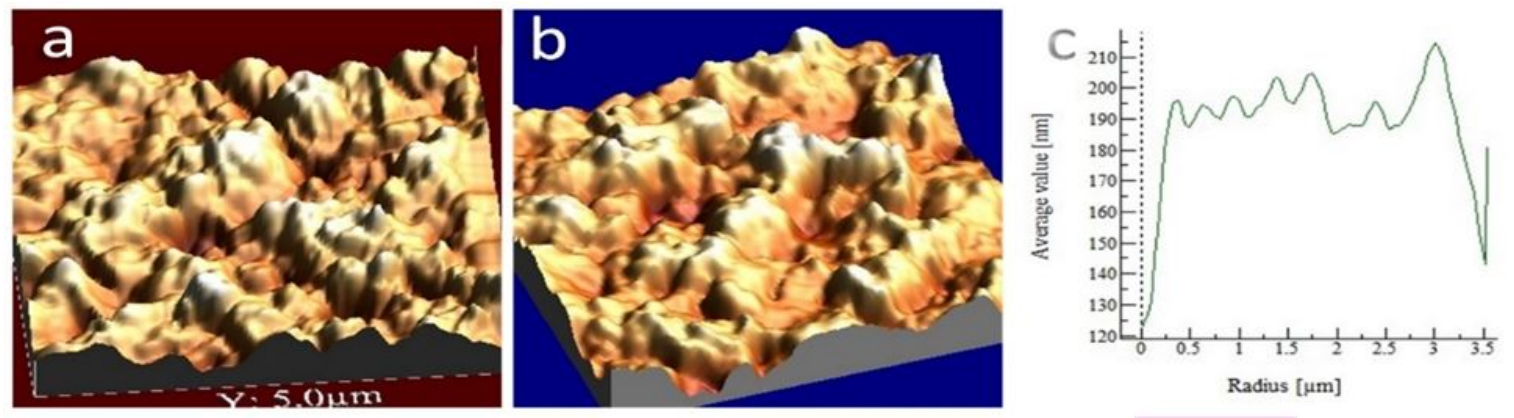

Figure 17: Cell surface roughness, (a) before plasma treatment, (b) after plasma treatment , (c) mean height. 
Table 3: Nano-scale surface height change: Transverse profile in terms of cell surface roughness.

\begin{tabular}{ccccc}
\hline & $R_{p v}$ & $R_{q}$ & $R_{a}$ & Mean Heigth \\
\hline Non-treated stem cell & 336.95 & 44.8525 & 35.6375 & 183 \\
Treated stem cell & 313.2 & 40.005 & 31.2025 & 166 \\
\hline
\end{tabular}

To characterize the surface topography, the amplitude parameters are the principal parameters. The average roughness $\left(R_{a}\right)$ and the root mean square roughness $\left(R_{q}\right)$ were used to determine roughness of the cell before and after treatment.

Arithmetic average height $\bar{Z}$, a general $\bar{Z}(N, M)=\frac{1}{N} \sum_{x=1}^{N} Z(x, y)$ description of height variations.

Average roughness $\left(R_{a}\right)$, gives the de- $R_{a}=\frac{1}{N} \sum_{x=1}^{N}(Z(x, y)-\bar{Z}(N, M))$ viation in height.

Root Mean Square (RMS) roughness $\left(R_{q}\right)$ represents the standard deviation $R_{q}(N, M)=\sqrt{\frac{1}{N} \sum_{x=1}^{N}(Z(x, y)-\bar{Z}(N, M))^{2}}$ of surface heights.

The results show in table 3 .

In the table $3, R_{a}$ is the average roughness, $R_{q}$ is the root mean square of roughness and $R_{\mathrm{pv}}$ is the maximum valley depth $\left(R_{v}\right)$ to maximum peak height $\left(R_{p}\right)$ in nm scale.

To make sure that the $R_{q}$ values are making sense, the height points need to be uniformly distributed according to a normal distribution. AFM analysis of both nontreated and plasma-treated cells indicated a topographic change in surface roughness at the nanometer scale during the plasma therapy. The uniformity of the topographic features of the stem cell surface increased after plasma exposure, as shown in Figure 17, in which the topography of the stem cells surface at the nanometer scale is showed. The transverse profile calculated with respect to the roughness data confirmed the nano-scale change in surface height (Table 3). Compared to non-treated cells, the topographic image of the plasma-treated cell in Figure 17-b showed a more uniform surface characteristic. Peak heights of max 110-200nm observed that were $10 \%$ lower than those observed in nontreated cells (125-225nm). These results showed that the roughness of the non-treated cell surface is almost $10 \%$ more (at the nanometer scale) than the treated cell. Consequently, given that the VDW force is inversely proportional to the distance between the two cells, it can be deduced that a $10 \%$ decrease in the distance between the two cells will increase the VDW force by up to around $20 \%$. This increase is simply due to the reduction in the gap between the two cells. For now, we have ignored the rise in VDW forces due to the smoothing of the cell surface. This amount is added to that of adhesion increased due to dipole formation and Hammaker coefficient change. 


\section{CONCLUSIONS}

The adhesion of the stem cells appears to be a key factor in determining their differentiation and fate. In this research, de-adhesion assays were utilized to evaluate stem cell adhesion after plasma treatment. Using this method, it was revealed that cell-ECM and cell-cell adhesions increased in a dose-dependent manner after plasma treatment. Experimental studies indicated an increase in the cell adhesion coefficient, for which two significant reasons were evoked following plasma treatment; 1) the improvement of integrin expression and activation which influence the cell-ECM adhesion and 2) the increasing of VDW force which increases the cell-cell adhesion. In this regard, in investigating the cellcell adhesion, the raise in VDW force obtained in suspension condition, to ignore the role of the integrin proteins, was due to three reasons; 1 ) the creation of electrical dipoles, 2) changing the dielectric constants of the culture medium and the cell-wall and, 3) decrement in the cell surface roughness. The rise in van der Waals force can be explained by an increase in dipole formation as a result of plasma treatment. Moreover, cell polarization was investigated both theoretically and experimentally, after plasma therapy. It was also discovered that plasma treatment enhances the Hammaker coefficient. Increasing in this coefficient indicates an increase in cell conductivity, which was evaluated in the current study. In accordance with the foregoing findings, it was revealed that the cell's surface had been modified as a result of being exposed to plasma. A change in the roughness of the cell surface might also explain the increase in van der Waals force. Taking all of the findings into account, it was revealed that the intercellular van der Waals force rises, as does the stem cell's adhesion. A change in the roughness of the cell surface might also explain the increase in van der Waals force. Taking into consideration all of the data, it was revealed that the intercellular van der Waals force, as well as the stem cell's adhesion, increases.

\section{References}

[1] G. Morfill, M. G. Kong, and J. Zimmermann, "Focus on plasma medicine," New Journal of Physics, vol. 11, no. 11, p. 115011, 2009.

[2] M. Vandamme, E. Robert, S. Pesnel, E. Barbosa, S. Dozias, J. Sobilo, S. Lerondel, A. Le Pape, and J.-M. Pouvesle, "Antitumor effect of plasma treatment on u 87 glioma xenografts: preliminary results," Plasma processes and polymers, vol. 7, no. 3-4, pp. 264-273, 2010.

[3] G. Collet, E. Robert, A. Lenoir, M. Vandamme, T. Darny, S. Dozias, C. Kieda, and J. M. Pouvesle, "Plasma jet-induced tissue oxygenation: potentialities for new therapeutic strategies," Plasma Sources Science and Technology, vol. 23, no. 1, p. 012005, 2014.

[4] M. Keidar, R. Walk, A. Shashurin, P. Srinivasan, A. Sandler, S. Dasgupta, R. Ravi, R. Guerrero-Preston, and B. Trink, "Cold plasma selectivity and the possibility of a paradigm shift in cancer therapy," British journal of cancer, vol. 105, no. 9, pp. 12951301, 2011. 
[5] G. Isbary, G. Morfill, H. Schmidt, M. Georgi, K. Ramrath, J. Heinlin, S. Karrer, M. Landthaler, T. Shimizu, B. Steffes, et al., "A first prospective randomized controlled trial to decrease bacterial load using cold atmospheric argon plasma on chronic wounds in patients," British Journal of Dermatology, vol. 163, no. 1, pp. 78-82, 2010.

[6] G. Isbary, W. Stolz, T. Shimizu, R. Monetti, W. Bunk, H.-U. Schmidt, G. E. Morfill, T. Klämpfl, B. Steffes, H. Thomas, et al., "Cold atmospheric argon plasma treatment may accelerate wound healing in chronic wounds: Results of an open retrospective randomized controlled study in vivo," Clinical Plasma Medicine, vol. 1, no. 2, pp. 2530, 2013.

[7] T. Maho, R. Binois, F. Brulé-Morabito, M. Demasure, C. Douat, S. Dozias, P. E. Bocanegra, I. Goard, L. Hocqueloux, C. L. Helloco, et al., "Anti-bacterial action of plasma multi-jets in the context of chronic wound healing," Applied Sciences, vol. 11, no. 20, p. 9598, 2021.

[8] A. A. Maradudin and P. Mazur, "Effects of surface roughness on the van der waals force between macroscopic bodies," Physical Review B, vol. 22, no. 4, p. 1677, 1980.

[9] L. Goitre, B. Pergolizzi, E. Ferro, L. Trabalzini, and S. F. Retta, "Molecular crosstalk between integrins and cadherins: do reactive oxygen species set the talk?," Journal of signal transduction, vol. 2012, 2012.

[10] T. R. Hurd, M. DeGennaro, and R. Lehmann, "Redox regulation of cell migration and adhesion," Trends in cell biology, vol. 22, no. 2, pp. 107-115, 2012.

[11] S. Di Meo, T. T. Reed, P. Venditti, and V. M. Victor, "Role of ros and rns sources in physiological and pathological conditions," Oxidative medicine and cellular longevity, vol. 2016, 2016.

[12] N. T. Moldogazieva, S. V. Lutsenko, and A. A. Terentiev, "Reactive oxygen and nitrogen species-induced protein modifications: implication in carcinogenesis and anticancer therapy," Cancer research, vol. 78, no. 21, pp. 6040-6047, 2018.

[13] A. Privat-Maldonado, A. Schmidt, A. Lin, K.-D. Weltmann, K. Wende, A. Bogaerts, and S. Bekeschus, "Ros from physical plasmas: Redox chemistry for biomedical therapy," Oxidative medicine and cellular longevity, vol. 2019, 2019.

[14] V. Vijayarangan, A. Delalande, S. Dozias, J.-M. Pouvesle, C. Pichon, and E. Robert, "Cold atmospheric plasma parameters investigation for efficient drug delivery in hela cells," IEEE Transactions on Radiation and Plasma Medical Sciences, vol. 2, no. 2, pp. 109-115, 2017.

[15] D. Lee, J. M. Park, S. H. Hong, and Y. Kim, "Numerical simulation on mode transition of atmospheric dielectric barrier discharge in helium-oxygen mixture," IEEE transactions on plasma science, vol. 33, no. 2, pp. 949-957, 2005.

[16] A. A. Khalili and M. R. Ahmad, "A review of cell adhesion studies for biomedical and biological applications," International journal of molecular sciences, vol. 16, no. 8, pp. 18149-18184, 2015. 
[17] S. Huang and D. E. Ingber, "The structural and mechanical complexity of cell-growth control," Nature cell biology, vol. 1, no. 5, pp. E131-E138, 1999.

[18] V. Vijayarangan, A. Delalande, S. Dozias, J.-M. Pouvesle, E. Robert, and C. Pichon, "New insights on molecular internalization and drug delivery following plasma jet exposures," International Journal of Pharmaceutics, vol. 589, p. 119874, 2020.

[19] J. S. Hale, M. Li, and J. D. Lathia, "The malignant social network: cell-cell adhesion and communication in cancer stem cells," Cell adhesion 83 migration, vol. 6, no. 4, pp. 346-355, 2012.

[20] B. J. Kirby, A. R. Wheeler, R. N. Zare, J. A. Fruetel, and T. J. Shepodd, "Programmable modification of cell adhesion and zeta potential in silica microchips," Lab on a Chip, vol. 3, no. 1, pp. 5-10, 2003.

[21] R. P. McEver and C. Zhu, "Rolling cell adhesion," Annual review of cell and developmental biology, vol. 26, pp. 363-396, 2010.

[22] M. S. Steinberg and P. M. McNutt, "Cadherins and their connections: adhesion junctions have broader functions," Current opinion in cell biology, vol. 11, no. 5, pp. 554-560, 1999.

[23] K. Kendall and A. Roberts, "van der waals forces influencing adhesion of cells," Philosophical Transactions of the Royal Society B: Biological Sciences, vol. 370, no. 1661, p. 20140078, 2015.

[24] E. Iwabuchi, Y. Miki, K. Takagi, Y. Onodera, Y. Shibahara, T. Ishida, T. Suzuki, and H. Sasano, "The expression of carcinoembryonic antigen-related cell adhesion molecule 6 and 8 in breast cancer," 2019.

[25] H. Perinpanayagam, R. Zaharias, C. Stanford, R. Brand, J. Keller, and G. Schneider, "Early cell adhesion events differ between osteoporotic and non-osteoporotic osteoblasts," Journal of orthopaedic research, vol. 19, no. 6, pp. 993-1000, 2001.

[26] S. Nir and M. Andersen, "Van der waals interactions between cell surfaces," The Journal of membrane biology, vol. 31, no. 1, pp. 1-18, 1977.

[27] G. Valchev, P. Djondjorov, V. Vassilev, and D. Dantchev, "Van der waals interactions between planar substrate and tubular lipid membranes undergoing pearling instability," in AIP Conference Proceedings, vol. 1895, p. 090002, AIP Publishing LLC, 2017.

[28] L. A. Lasky, M. S. Singer, D. Dowbenko, Y. Imai, W. J. Henzel, C. Grimley, C. Fennie, N. Gillett, S. R. Watson, and S. D. Rosent, "An endothelial ligand for l-selectin is a novel mucin-like molecule," Cell, vol. 69, no. 6, pp. 927-938, 1992.

[29] S. Hirohashi and Y. Kanai, "Cell adhesion system and human cancer morphogenesis," Cancer science, vol. 94, no. 7, pp. 575-581, 2003.

[30] T. Okegawa, R.-C. Pong, Y. Li, and J.-T. Hsieh, "The role of cell adhesion molecule in cancer progression and its application in cancer therapy.," Acta Biochimica Polonica, vol. 51, no. 2, pp. 445-457, 2004. 
[31] Z. Trošt, R. Trebše, J. Preželj, R. Komadina, D. B. Logar, and J. Marc, "A microarray based identification of osteoporosis-related genes in primary culture of human osteoblasts," Bone, vol. 46, no. 1, pp. 72-80, 2010.

[32] B. Haertel, T. Von Woedtke, K.-D. Weltmann, and U. Lindequist, "Non-thermal atmospheric-pressure plasma possible application in wound healing," Biomolecules $\& 5$ therapeutics, vol. 22, no. 6, p. 477, 2014.

[33] B. Haertel, K. Wende, T. von Woedtke, K. D. Weltmann, and U. Lindequist, "Nonthermal atmospheric-pressure plasma can influence cell adhesion molecules on hacatkeratinocytes," Experimental dermatology, vol. 20, no. 3, pp. 282-284, 2011.

[34] K. Pai, C. Timmons, K. D. Roehm, A. Ngo, S. S. Narayanan, A. Ramachandran, J. D. Jacob, L. M. Ma, and S. V. Madihally, "Investigation of the roles of plasma species generated by surface dielectric barrier discharge," Scientific reports, vol. 8, no. 1, pp. 1-13, 2018.

[35] M. Keidar, A. Shashurin, O. Volotskova, M. Ann Stepp, P. Srinivasan, A. Sandler, and B. Trink, "Cold atmospheric plasma in cancer therapy," Physics of Plasmas, vol. 20, no. 5, p. 057101, 2013.

[36] O. Volotskova, M. A. Stepp, and M. Keidar, "Integrin activation by a cold atmospheric plasma jet," New Journal of Physics, vol. 14, no. 5, p. 053019, 2012.

[37] K. Hajizadeh, K. Hajisharifi, and H. Mehdian, "Morphological risk assessment of cold atmospheric plasma-based therapy: bone marrow mesenchymal stem cells in treatment zone proximity," Journal of Physics D: Applied Physics, vol. 52, no. 49, p. 495203, 2019.

[38] H. Wilson, "On some phenomena of coalescence and regeneration in sponges," Journal of the Elisha Mitchell Scientific Society, vol. 23, no. 4, pp. 161-174, 1907.

[39] J. S. Huxley, "V. some phenomena of regeneration in sycon: with a note on the structure of its collar-cells," Philosophical Transactions of the Royal Society of London. Series B, Containing Papers of a Biological Character, vol. 202, no. 282-293, pp. 165-189, 1912.

[40] S. Sen and S. Kumar, "Cell-matrix de-adhesion dynamics reflect contractile mechanics," Cellular and molecular bioengineering, vol. 2, no. 2, pp. 218-230, 2009.

[41] U. Horzum, B. Ozdil, and D. Pesen-Okvur, "Step-by-step quantitative analysis of focal adhesions," MethodsX, vol. 1, pp. 56-59, 2014.

[42] B. Haertel, S. Straßenburg, K. Oehmigen, K. Wende, T. von Woedtke, and U. Lindequist, "Differential influence of components resulting from atmospheric-pressure plasma on integrin expression of human hacat keratinocytes," BioMed research international, vol. 2013, 2013.

[43] S. U. Kang, J. W. Choi, J. W. Chang, K. I. Kim, Y. S. Kim, J. K. Park, Y. E. Kim, Y. S. Lee, S. S. Yang, and C.-H. Kim, "N2 non-thermal atmospheric pressure plasma promotes wound healing in vitro and in vivo: Potential modulation of adhesion 
molecules and matrix metalloproteinase-9," Experimental dermatology, vol. 26, no. 2, pp. 163-170, 2017.

[44] F. Podo, "Dielectric and electronic properties of biological materials: R. pethig, john wiley \& sons, chichester, new york, brisbane, toronto (1979), xiv + 376 pp.,£ 15.00.," 1979 .

[45] G. Cevc, "Membrane electrostatics," Biochimica et Biophysica Acta (BBA)-Reviews on Biomembranes, vol. 1031, no. 3, pp. 311-382, 1990.

[46] E. Carstensen and R. Marquis, "Passive electrical properties of microorganisms: Iii. conductivity of isolated bacterial cell walls," Biophysical journal, vol. 8, no. 5, pp. 536-548, 1968.

[47] E. Carstensen and R. Marquis, "Dielectric and electrochemical properties of bacterial cells," Spores VI. American Society for Microbiology, Washington, DC, pp. 563-571, 1975 .

[48] A. James, "The electrical properties and topochemistry of bacterial cells," Advances in colloid and Interface Science, vol. 15, no. 3-4, pp. 171-221, 1982.

[49] P. Bongrand, P. M. Claesson, and A. S. Curtis, Studying cell adhesion. Springer Science \& Business Media, 2013. 